\title{
Optimization of L-Tryptophan Biosynthesis From L-Serine of Processed Iranian Beet and Cane Molasses and Indole by Induced Escherichia coli ATCC 11303 Cells
}

\author{
Tahereh Sadeghiyan-Rizi ${ }^{1, *}$; Jamshid Fooladi ${ }^{2}$; Majid Momhed Heravi ${ }^{3}$; Sima Sadrai ${ }^{4}$ \\ ${ }^{1}$ Department of Pharmaceutical Biotechnology, Faculty of Pharmacy, Isfahan University of Medical Sciences, Isfahan, IR Iran \\ ${ }_{3}^{2}$ Department of Biology, National Laboratory of Industrial Microbiology, Faculty of Science, Alzahra University, Tehran, IR Iran \\ 3 Department of Chemistry, Faculty of Science, Alzahra University, Tehran, IR Iran \\ 4 Department of Pharmaceutics, Faculty of Pharmacy, Tehran University of Medical Sciences, Tehran, IR Iran \\ ${ }^{*}$ Corresponding author: Tahereh Sadeghiyan-Rizi, Department of Pharmaceutical Biotechnology, Faculty of Pharmacy, Isfahan University of Medical Sciences, Isfahan, IR Iran. Tel: \\ +98-3117922571, E-mail: sadeghiyantahereh@yahoo.com \\ Received: February 5, 2013; Revised:April 25, 2013; Accepted: May 5, 2013
}

\begin{abstract}
Background: L-tryptophan is an important ingredient in medicines, especially in neuromedicines such as antidepressants. Many commercial processes employ various microorganisms with high tryptophan synthase activity to produce L-tryptophan from indole and L-serine, but these processes are very costly due to the costs of precursors, especially L-serine.

Objectives: For this reason, we studied the ability to use processed Iranian cane and beet molasses as L-serine sources for L-tryptophan production, which enables us to reach a cost-effective process.

Materials and Methods: Whole cells of Escherichia coli ATCC 11303 were induced for L-tryptophan synthase by addition of indole to the growth medium and bacterial cells harvested from the growth medium were used as biocatalysts in the production medium. Conditions of the production medium were optimized and Iranian cane and beet molasses were processed by solvent extraction with ethanol and n-butanol and used as L-serine sources of the production medium. Amount of L-tryptophan and theoretical yield of L-tryptophan production were determined by High Performance Liquid Chromatography and by a colorimetrical method on the basis of the remaining indole assay, respectively.

Results: L-tryptophan production increased by 15 folds, when indole was used as an inducer. L-tryptophan was produced from processed Iranian beet molasses in satisfactory amounts $(0.53 \mathrm{mM})$ and no exogenous pyridoxal phosphate was required as a cofactor under our experimental conditions.

Conclusions: The obtained results proved that Iranian beet molasses include significant amounts of L-serine that makes them a suitable substitution for L-serine. Findings of the present study give impetus to use of Iranian beet molasses for cost-effective L-Trp production in the amino acid industry.
\end{abstract}

Keywords:Tryptophan; Tryptophan Synthase; Indole

\section{Background}

L-tryptophan (L-Trp) is a fundamental precursor of various neurotransmitters in the brain, which are essential for the regulation of mood, sleep, appetite and pain level, such as melatonin, niacin and serotonin (1-7). It is used widespread in the pharmaceutical industry for the chemical synthesis of a range of drugs such as antidepressants, sedative pharmaceuticals and drugs used for the treatment of schizophrenia and alcoholism (8, 9). It is also used as a food supplement in animal feeds (10). There are chemical and microbial processes for L-Trp production. All chemical synthesis yield DL-Tryptophan and the product must be resolved for the separation of the biologically active L-isomer (11). The majority of L-Trp production depends on microbial processes. These processes include direct fermentation from carbohydrates or hydrocarbons, enzymatic reaction from L-Trp precursors and bioconversion from L-Trp precursors. Effective production processes are available with mutants of Escherichia coli (12), Corynebacterium glutamicum (13), Bacillus subtilis (14) and Brevibacterium lactofermentum (15).

Although, many industrial processes employ E. coli cells which have L-tryptophan synthase (TSase, EC 4.2.1.20) activity to convert indole and L-serine (L-Ser) to L-Trp (16); since this type of production is based on a very simple and one-step reaction therefore the complete biosynthetic pathway of L-Trp isn't necessary and the complicated mutations of microorganisms which control the regulatory mechanisms are often not required (17). However, there are disadvantages to these processes because precursors are expensive. Indole is available from the petrochemical

Implication for health policy/practice/research/medical education:

Application of L-Tryptophan (L-Trp) is widespread in pharmaceutical and animal feed industry. Many commercial processes employ various microorganisms with high tryptophan synthase activity to produce L-tryptophan from indole and L-serine, but these processes are very costly due to the costs of precursors, especially L-serine. The cost-effective production of L-Trp has gradually attracted the attention of the amino acid industry. Use of cane and beet molasses as the L-serine source of L-tryptophan production enables us to reach a cost-effective process.

Copyright (C) 2014,Ahvaz Jundishapur University of Medical Sciences; Published by Kowsar Corp. This is an open-access article distributed under the terms of the Creative Commons Attribution License, which permits unrestricted use, distribution, and reproduction in any medium, provided the original work is properly cited. 
Sadeghiyan-Rizi Tet al.

\begin{tabular}{lcccc}
\hline \multicolumn{1}{l}{ Table 1. Iranian Cane and Beet Molasses Composition ${ }^{\mathrm{a}}$} & & & \\
\hline- & Polarity, $\%$ & Brix, $\%$ & Purity, $\%$ & pH \\
\hline Orumiyeh beet molasses & 46.2 & 77.3 & 59.77 & 6.4 \\
Karaj cane molasses & 36.8 & 62.5 & 58.88 & 7 \\
Fariman cane molasses & 34.6 & 60.3 & 57.38 & 7 \\
\hline
\end{tabular}

${ }^{\mathrm{a}}$ Polarity = Sucrose content $(\mathrm{g} / 100 \mathrm{~mL}$ molasses $)$; Brix = total soluble solids $(\mathrm{w} / \mathrm{w}) ;$ Purity\% $=($ Polarity $/$ Brix $) \times 100$

industry as a comparably inexpensive educt, whereas LSer is very expensive because a racemic mixture is formed during its manufacture. To address this problem, new methods for both process design and cheap precursor substitution have been developed, for example production of L-Ser from methanol and glycine by methanolutilizing bacteria (17-19). Recovery of L-Ser from the byproducts of various industries provides another means that may be more efficient than the latter.

\section{Objectives}

The present research aimed to bacterial cell propagation in the culture medium containing beet molasses as an inexpensive carbon source and indole as a Tryptophan Synthase inducer, optimization of production medium conditions and use of induced bacterial cells as biocatalysts of L-Trp production from indole and processed Iranian cane and beet molasses as the sole L-Ser source of production medium.

\section{Materials and Methods}

\subsection{Chemicals}

Indole, L-serine (L-Ser), pyridoxal phosphate (PLP), L-Trp, n-butanol and methanol were purchased from Merck (Germany) and all other chemicals were analytical grades or the highest purity commercially available. Cane and beet molasses were obtained from three Iranian sugar industries, cane and beet composition are presented in Table 1.

\subsection{Microorganism and Culture Conditions}

E. coli ATCC 11303 was used in this research. The strain was maintained on an agar slant prepared from a complete medium containing glucose $(20 \mathrm{~g} / \mathrm{L})$, yeast extract $(25 \mathrm{~g} / \mathrm{L})$, ammonium sulphate $(0.5 \mathrm{~g} / \mathrm{L})$ and agar $(15 \mathrm{~g} / \mathrm{L})$. Bacterial colonies were inoculated in a $500 \mathrm{~mL}$ Erlenmeyer flask containing $100 \mathrm{~mL}$ of complete medium (as pre-culture) and incubated on a rotary shaker $(180 \mathrm{rpm})$ at $37{ }^{\circ} \mathrm{C}$ for five hours. The cells recovered from $10 \mathrm{~mL}$ of pre culture medium were resuspended in $10 \mathrm{~mL}$ of $0.9 \% \mathrm{NaCl}$ solution and $1 \mathrm{~mL}$ of this suspension was inoculated to a $500 \mathrm{~mL}$ Erlenmeyer flask containing $100 \mathrm{~mL}$ of growth medium composed of $\mathrm{K}_{2} \mathrm{HPO}_{4}(7 \mathrm{~g} / \mathrm{L}), \mathrm{KH}_{2} \mathrm{PO}_{4}(3 \mathrm{~g} / \mathrm{L}), \mathrm{Na}_{3}$.citrate. $3 \mathrm{H}_{2} \mathrm{O}(0.5$ $\mathrm{g} / \mathrm{L}), \mathrm{MgSO}_{4} \cdot 7 \mathrm{H}_{2} \mathrm{O}(0.1 \mathrm{~g} / \mathrm{L})$ and beet molasses $(16.2 \mathrm{~g} / \mathrm{L})$. After 6.5 hours of incubation in conditions mentioned above, indole $(0.058 \mathrm{~g} / \mathrm{L})$ was added to the growth medium and incubation was continued for up to ten hours. The cells of stationary phase were harvested and used in L-Trp production medium as a biocatalyst. Polarity\% of beet molasses ( $\mathrm{g}$ sucrose/100 mL beet molasses) was $42.2 \%$. Accordingly, 10.8 $\mathrm{mL}$ of beet molasses equal to $16.2 \mathrm{~g}$, contained $5 \mathrm{~g}$ sucrose and was used as a carbon source for the culture medium.

\subsection{Determination of Cell Growth}

The growth of microorganisms was determined periodically by measuring the optical density at $620 \mathrm{~nm}$, every one hour. For determination of biomass weight, culture medium was centrifuged and the harvested cell mass was washed twice and weighted (20).

\subsection{Molasses Processing}

Each of the two samples of cane and one sample of beet molasses $(50 \mathrm{~mL})$ were diluted by distilled water (1:1), mixed with ethanol 96\% (1:1) and kept at $4^{\circ} \mathrm{C}$ overnight, in order to precipitate macromolecules (such as protein, oligosaccharide, etc.) and dye. After solvent evaporation, the residue was mixed with n-butanol (1:1); the mixture was vigorously vortexed and incubated at room temperature for one hour. After formation of two phases, the organic phase was separated and n-butanol was evaporated. The residue from each molasses was used instead of L-Ser in L-Trp production medium.

\subsection{Tryptophan Production}

Biomass harvested from culture medium ( $3 \mathrm{~g}$ ) was transferred to a $500 \mathrm{~mL}$ Erlenmeyer flask containing production medium (100 mL potassium phosphate buffer (0.1 M, pH = 8), indole (0.05 g) and L-Ser (0.05 g) incubated in a rotary shaker $(180 \mathrm{rpm})$ at $37{ }^{\circ} \mathrm{C}$. After four hours of incubation, the production medium was centrifuged at $12000 \mathrm{rpm}$ for 20 minutes at $4^{\circ} \mathrm{C}$ and the supernatant fluid was used for the assay of the produced L-Trp and the remaining indole.

L-Trp was detected by High Performance Liquid Chromatography in a Waters system equipped with an isocratic pump and an ultraviolet detector, by using an RP-18 column (MZ-analytical column, $4 \times 100 \mathrm{~mm}$ ) with $3 \mu \mathrm{m}$ particle size; the mobile phase was phosphate buffer (0.05 M, pH = 4.2): methanol (70:30). Injection volume, flow rate and $\lambda_{\text {absorbance }}$ were $50 \mu \mathrm{L}, 1.2 \mathrm{ml} / \mathrm{min}$ and 220 $\mathrm{nm}$, respectively $(21,22)$. For sample analysis, L-Trp was dissolved to a concentration of $1 \mathrm{mg} / \mathrm{mL}$ with purified wa- 
ter as stock solution. L-Trp concentrations of 5, 4, 2, 1, $0.5,0.2,0.1$ and $0.05 \mu \mathrm{g} / \mathrm{mL}$ were prepared with purified water from stock solution and used for the standard curve. L-Trp concentration in the supernatant fluid of the production medium was determined according to the standard curve. AT 3000 Autochor software was used for HPLC data analysis. Consumed indole and the theoretical yield of L-Trp production was determined colorimetrically on the basis of the remaining indole in the supernatant fluid of production medium, determined spectrophotometrically at $490 \mathrm{~nm}$ (23).

\subsection{Effect of Indole on Cell Growth and L-Trp Pro- duction}

Indole has bacteriostatic effects on bacterial cells at specific concentrations (24). In this research indole presence in culture medium as the TSase inducer was investigated, thus it was a pre-requsite to determine the effect of indole on bacterial cells growth. E. coli ATCC 11303 was grown in the three culture media, one being without indole (control sample), and the two others with $0.058 \mathrm{~g} / \mathrm{L}$ of indole; in one indole was added at the beginning (sample 1) and in the other it was added near to the end of the logarithmic phase, i.e. after 6.5 hours of growth medium incubation (sample 2). Next, $1 \mathrm{~g}$ of bacterial cells harvested from each of the three samples was transferred to the production medium containing $0.005 \mathrm{~g}$ of pyridoxal phasphate in addition to L-Ser and indole (0.05 g) and incubated for six hours. Cell growth was determined by measuring biomass weight during logarithmic, end of logarithmic and stationary phases in control samples and sample 1. Also L-Trp produced by biomass harvested from the three samples was compared to each other.

\subsection{Effect of PLP, Time Course of Reaction and Bio- catalyst Amount on L-Tryptophan Production}

To establish the most advantageous production conditions, various parameters were optimized. TSase is a PLPdependent enzyme (25). Exogenous PLP requirements as the cofactor of the reaction was investigated by addition of different PLP concentrations (0, 0.005, 0.01 and 0.02 g/100 $\mathrm{mL}$ ) to the production medium and incubation for 6 hours, after which L-Trp produced by the $1 \mathrm{~g}$ biomass in the four production media were compared with each other. TSase and tryptophanase (TPase, EC 4.1.99.1) are both present in $E$. coli. TPase catalyzes the conversion of L-Trp to pyruvate, ammonia and indole while L-Trp concentration increases (26). To check when L-Trp degradation begins under our experimental conditions, production medium was incubated for 6 hours, sampling was done every one hour, produced LTrp and remaining indole in each sample was assayed and optimum time course of the reaction was determined. The optimal amount of biocatalyst for L-Trp production was determined by the use of production medium containing different amounts of biocatalyst $(1,2,3,4$ and $5 \mathrm{~g} / 100 \mathrm{~mL})$ incubated for four hours. Optimal biocatalyst amount was
Figure 1. Effect of Indole on Growth of E. coli ATCC 11303

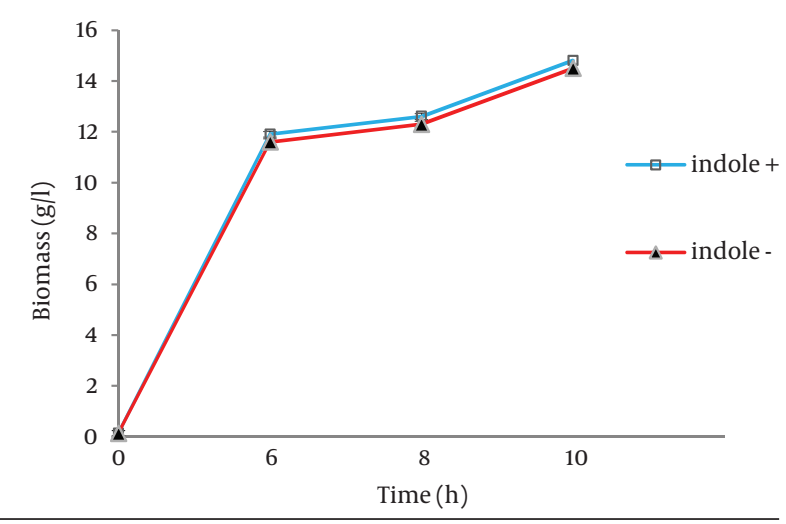

The Organism was grown at $37{ }^{\circ} \mathrm{C}$ and $180 \mathrm{rpm}$ in the following media: $\Delta$ Growth medium containing $\mathrm{K}_{2} \mathrm{HPO}_{4}(7 \mathrm{~g} / \mathrm{L}), \mathrm{KH}_{2} \mathrm{PO}_{4}(3 \mathrm{~g} / \mathrm{L}), \mathrm{Na}_{3}$. citrate. $3 \mathrm{H}_{2} \mathrm{O}(0.5 \mathrm{~g} / \mathrm{L}), \mathrm{MgSO}_{4} .7 \mathrm{H}_{2} \mathrm{O}(0.1 \mathrm{~g} / \mathrm{L})$ and beet molasses $(16.2 \mathrm{~g} / \mathrm{L})$ (control sample); $\square$ Growth medium containing $\mathrm{K}_{2} \mathrm{HPO}_{4}(7 \mathrm{~g} / \mathrm{L}), \mathrm{KH}_{2} \mathrm{PO}_{4}$ $(3 \mathrm{~g} / \mathrm{L}), \mathrm{Na}_{3}$.citrate. $3 \mathrm{H}_{2} \mathrm{O}(0.5 \mathrm{~g} / \mathrm{L}), \mathrm{MgSO}_{4} .7 \mathrm{H}_{2} \mathrm{O}(0.1 \mathrm{~g} / \mathrm{L})$, beet molasses $(16.2 \mathrm{~g} / \mathrm{L})$ and $0.058 \mathrm{~g} / \mathrm{L}$ indole (sample 1$)$.

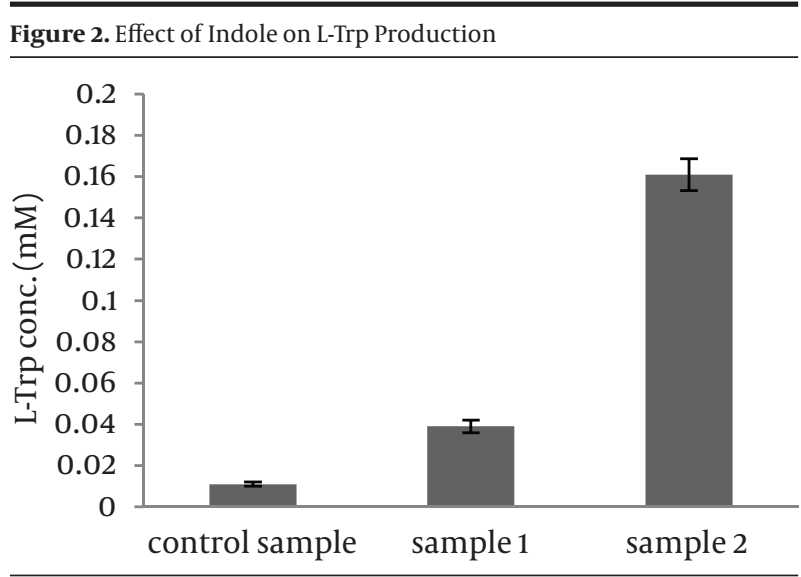

Biomass harvested from the growth medium containing $\mathrm{K}_{2} \mathrm{HPO}_{4} 7 \mathrm{~g} / \mathrm{L}$, $\mathrm{KH}_{2} \mathrm{PO}_{4} 3 \mathrm{~g} / \mathrm{L}, \mathrm{Na}_{3}$.citrate. $3 \mathrm{H}_{2} \mathrm{O} 0.5 \mathrm{~g} / \mathrm{L}, \mathrm{MgSO}_{4} .7 \mathrm{H}_{2} \mathrm{O} 0.1 \mathrm{~g} / \mathrm{L}$ and beet molasses $16.2 \mathrm{~g} / \mathrm{L}$ (control sample) was transferred to the production medium (1); Biomass harvested from the growth medium containing $\mathrm{K}_{2} \mathrm{HPO}_{4} 7 \mathrm{~g} / \mathrm{L}$, $\mathrm{KH}_{2} \mathrm{PO}_{4} 3 \mathrm{~g} / \mathrm{L}, \mathrm{Na}_{3}$. citrate. $3 \mathrm{H}_{2} \mathrm{O} 0.5 \mathrm{~g} / \mathrm{L}, \mathrm{MgSO}_{4} .7 \mathrm{H}_{2} \mathrm{O} 0.1 \mathrm{~g} / \mathrm{L}$, beet molasses $16.2 \mathrm{~g} / \mathrm{L}$ and indole $0.058 \mathrm{~g} / \mathrm{L}$ (sample 1 ) was transferred to the production medium (2); Biomass harvested from the growth medium containing $\mathrm{K}_{2} \mathrm{HPO}_{4} 7 \mathrm{~g} / \mathrm{L}, \mathrm{KH}_{2} \mathrm{PO}_{4} 3 \mathrm{~g} / \mathrm{L}, \mathrm{Na}_{3}$. citrate. $3 \mathrm{H}_{2} \mathrm{O} 0.5 \mathrm{~g} / \mathrm{L}, \mathrm{MgSO}_{4} .7 \mathrm{H}_{2} \mathrm{O} 0.1 \mathrm{~g} / \mathrm{L}$, beet molasses $16.2 \mathrm{~g} / \mathrm{L}$ and indole $0.058 \mathrm{~g} / \mathrm{L}$ (that was added to it after 6.5 hours of growth medium incubation (sample 2), was transferred to the production medium (3) and incubated at $37^{\circ} \mathrm{C}$ and $180 \mathrm{rpm}$ for six hours.

appointed by comparison of L-Trp production and indole consumption among these samples.

\subsection{Investigation of L-Trp Production by Processed Iranian Beet and Cane Molasses}

After optimization of tryptophan production conditions, Iranian cane and beet molasses capability to be used as an L-Ser source of the production medium was investigated. LSer of theproduction medium was displaced with processed Orumiyeh (northwest of Iran) beet molasses and Karaj (center of Iran) and Fariman (northeast of Iran) cane molasses. 


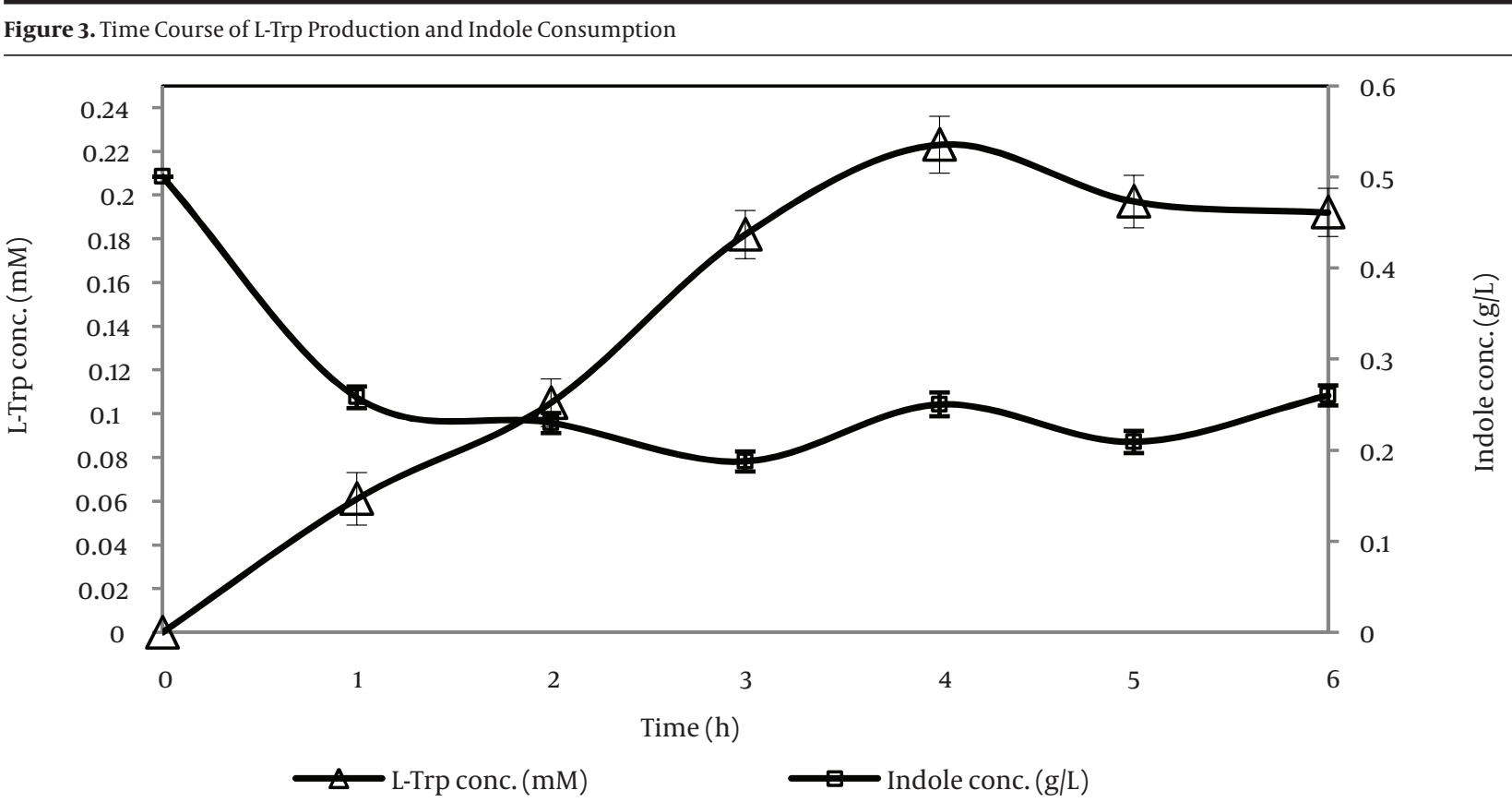

Time Course of L-Trp Production ( $\Delta$ ) and Indole Consumption by E. coli ATCC 11303 in a Production Medium Containing L-Ser and indole (0.5 g/L) Incubated at $37^{\circ} \mathrm{C}$ and 180 rpm for six Hours.

Table 2. Effect of PLP on L-Trp Production ${ }^{\text {a }}$

\begin{tabular}{lc}
\hline Concentration of PLP, $\mathbf{g} / \mathbf{L}$ & L-Trp Concentration, $\mathbf{m M}$ \\
\hline None & 0.187 \\
$\mathbf{0 . 0 5}$ & 0.158 \\
$\mathbf{0 . 1}$ & 0.103 \\
$\mathbf{0 . 2}$ & 0.064 \\
\hline
\end{tabular}

${ }^{a}$ Abbreviations: L-Trp, L-tryptophan; PLP, pyridoxal phosphate.

Since other components except L-Ser might exist in processed molasses and affect the reaction, the production medium was incubated for a longer duration i.e.10 hours and sampling was done at four, eight and ten hours. Since processed molasses might contain L-Trp and interfere in the results, L-Trp existing in the production medium was calculated before incubation (T0).

\subsection{Statistical Method}

The experiments were carried out in triplicates. All the results were analyzed statistically by one-way analysis of variance and Tukey's test with 95\% confidence level using Minitab 15.2.

\section{Results}

\subsection{Effect of Indole on Cell Growth and L-Trp Pro- duction}

As shown in Figure 1, bacterial growth was not affected by indole addition to the growth culture. Results showed that L-Trp produced by the biocatalyst, grown in sample 1 and sample 2, was increased by 3.7 and 15 folds, respectively (Figure 2). Therefore, indole addition to the growth medium was carried out 6.5 hours after growth medium incubation for subsequent experiments.

\subsection{Effect of PLP, Time Course of Reaction and Bio- catalyst Amount on L-Trp Production}

It was indicated that no exogenous PLP was needed under our experimental conditions (Table 2). As shown in Figure 3, L-Trp production increased for up to four hours and this period, it decreased due to degradation by TPase. On the other hand, the remaining indole gradually decreased for up to three hours and after this period it increased, therefore the best time course for L-Trp production was four hours and L-Trp production was stopped at four hours in subsequent tests. As shown in Figure 4, most of the L-Trp production was obtained by use of $3 \mathrm{~g}$ of biomass. After optimization of production parameters, theoretical yield of L-Trp production reached $37.4 \%$.

\subsection{Investigation of Processed Molasses Usage In- stead of L-Ser}

L-Trp was produced from processed Orumiyeh beet molasses as the L-Ser source of reaction; whereas processed cane molasses didn't contain L-Ser and L-Trp was not produced by use of them as the L-Ser source in the reaction mixture (Table 3 ). 
Figure 4. Effect of Biocatalyst Amount on L-Trp Production and Indole Consumption

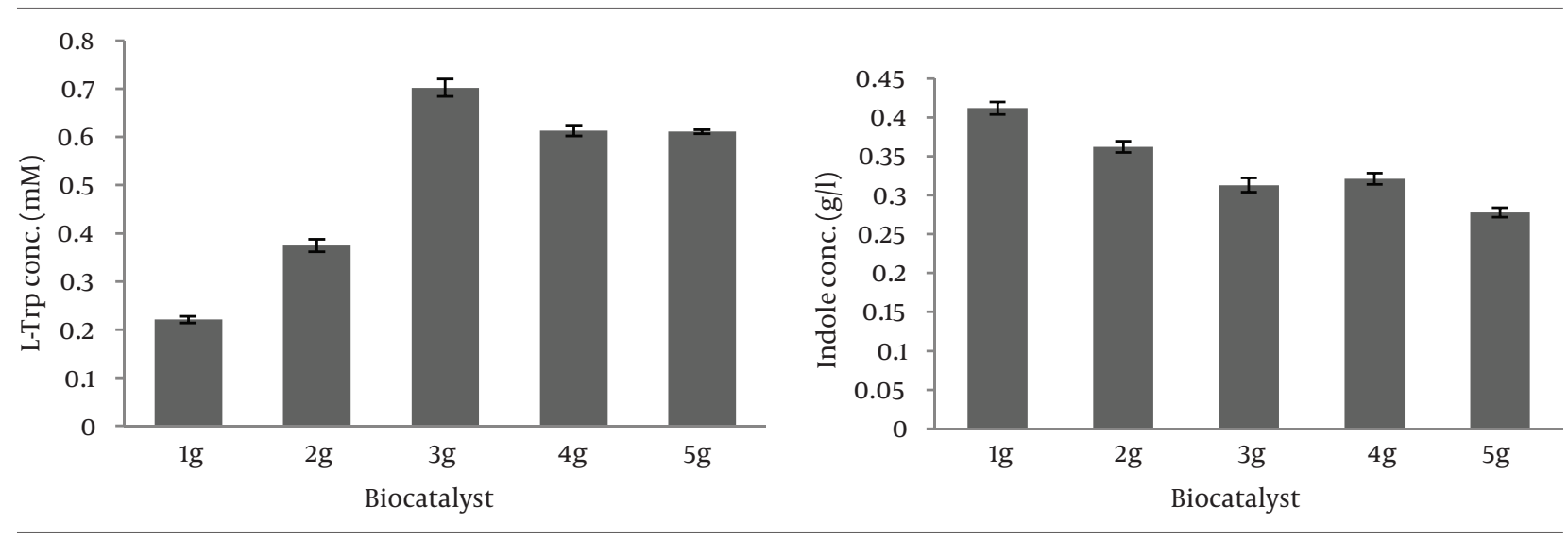

Effect of Biocatalyst Amount on L-Trp Production (A) and Indole Consumption (B) by Biomass (1-5 g/100 mL) of E. coli ATCC 11303 in the Production Medium Containing L-Ser and Indole $(0.5 \mathrm{~g} / \mathrm{L})$ Incubated at $37^{\circ} \mathrm{C}$ and $180 \mathrm{rpm}$ for Four Hours.

\begin{tabular}{|c|c|c|c|c|}
\hline \multirow[t]{2}{*}{ L-Ser Source of Production Medium } & \multicolumn{4}{|c|}{ L-Trp Concentration, $\mathrm{mM}$} \\
\hline & o Hour ${ }^{a}$ & 4 Hours & 8 Hours & 10 Hours \\
\hline Orumiyeh beet molasses & 0.025 & 0.173 & 0.53 & 0.447 \\
\hline Fariman cane molasses & 0.0007 & 0.0004 & 0 & 0 \\
\hline Karaj cane molasses & 0 & 0 & 0 & 0 \\
\hline L-Ser & 0 & 0.702 & - & - \\
\hline
\end{tabular}

\section{Discussion}

The cost-effective production of L-Trp has gradually attracted the attention of the amino acid industry (11). In our previous work, cane molasses (27) and combination of cane and beet molasses accompanied by $0.35 \mathrm{~g} / \mathrm{L}$ L-Ser (28) were used as L-Ser sources in the production medium. In the present study, L-Trp production was improved by optimization of culture and production medium conditions and processing of beet molasses before use as the sole L-Ser source, consequently L-Trp production reached $0.53 \mathrm{mM}$ (Table 3 ).

Beet molasses was used not only as the L-Ser source in the production medium but also as the carbon source in the culture medium. Beet molasses contains relatively large amounts of sucrose, amino acids and vitamins such as pyridoxine (29). For this reason, in our study use of beet molasses as the carbon source of culture medium not only accelerated the bacterial cells growth but also these cells gained a significant amount of PLP from the culture medium and when used as a biocatalyst in the production medium, they didn't require exogenous PLP as a cofactor of TSase (Table 2) whereas in previous reports exogenous PLP was needed (10, 11, 13, 16, 17, 30-32); this finding is very important from an economical point of view.

In this research, inducer effect of indole was proved by the fifteen-fold increase in L-Trp production. Also it was found that indole addition near to the end of the logarithmic phase was more effective because L-Trp as well as other amino acids is produced in the stationary phase (Figure 2). Langrene et al. (33) used three-indolacrylic acid and observed an increased L-Trp production by ten folds. As the main result, L-Trp was produced from processed Orumiyeh beet molasses, as the L-Ser source. Although, it was observed that use of processed beet molasses as the L-Ser source of production medium leads to a $17.2 \%$ decrease in L-Trp production compared to when L-Ser was used (Table 3). This was expected, since processed beet molasses contain considerable amounts of L-Trp (0.025 $\mathrm{mM}$ in the reaction mixture, on the other hand 1.02 $\mathrm{mg} / 50 \mathrm{~mL}$ molasses) (Table 3 ) and L-Trp is a strong inhibitor of L-Trp production.

In a report by Mateus et al. (9) an initial L-Trp led to a decrease in its initial production rate. The two samples of cane molasses used in this study didn't have enough L-Ser, and L-Trp was not produced in their presence (Table 3), whereas in a previous study (27) L-Trp was produced from the L-Ser content of cane molasses. The samples of cane molasses used in the two studies were prepared from different sugar factories and it has been proved that composition of molasses is influenced by factors such as 
soil type, ambient temperature, moisture, variety, production practices at a particular processing plant and storage variables $(34,35)$. In this research, we proved that Iranian beet molasses includes significant amounts of LSer that makes it a suitable substitution for L-Ser in L-Trp production. Findings of the present study give impetus to the use of Iranian beet molasses for cost-effective L-Trp production on an industrial scale. However, further experimentation to obtain more pure L-Ser fractions from Iranian molasses and consequently more production of L-Trp promises to shed more light on this subject and our future work will be aimed at recovery of L-Ser from beet molasses using ion-exclusion and ion-exchange chromatography.

\section{Acknowledgements}

We gratefully acknowledge the support of the National Laboratory of Industrial Microbiology, Alzahra University and Biopharmacy Laboratory of Tehran University of Medical Sciences.

\section{Authors' Contributions}

Tahereh Sadeghiyan-rizi (60\%), Jamshid Fooladi (25\%), Majid-Momhed Heravi (5\%) and Sima Sadrai (10\%).

\section{Financial Disclosure}

This research is a section of the M.S thesis of T. Sadeghiyan and has supported financially by the department of Biology of Alzahra University (Tehran, Iran).

\section{Funding/Support}

This research is a section of the MSc thesis of T. Sadeghiyan and has supported financially by the department of Biology of Alzahra University (Tehran, Iran).

\section{References}

1. Robinson OJ, Sahakian BJ. Acute tryptophan depletion evokes negative mood in healthy females who have previously experienced concurrent negative mood and tryptophan depletion. Psychopharmacology (Berl). 2009;205(2):227-35.

2. Riemann D, Feige B, Hornyak M, Koch S, Hohagen F, Voderholzer U. The tryptophan depletion test: impact on sleep in primary insomnia - a pilot study. Psychiatry Res. 2002;109(2):129-35.

3. Fernstrom JD. Tryptophan, serotonin and carbohydrate appetite: will the real carbohydrate craver please stand up! J Nutr 1988;118(11):1417-9.

4. Messonnier S. Questions tryptophan dosage and pain tolerance. J Am Vet Med Assoc. 2000;217(7):988-9.

5. Paredes SD, Marchena AM, Bejarano I, Espino J, Barriga C, Rial RV, et al. Melatonin and tryptophan affect the activity-rest rhythm, core and peripheral temperatures, and interleukin levels in the ringdove: changes with age. J Gerontol A Biol Sci Med Sci. 2009;64(3):340-50.

6. Egashira Y, Nagaki S, Sanada H. Tryptophan-niacin metabolism in rat with puromycin aminonucleoside-induced nephrosis. Int J Vitam Nutr Res. 2006;76(1):28-33.

7. Mateos SS, Sanchez CL, Paredes SD, Barriga C, Rodriguez AB. Circadian levels of serotonin in plasma and brain after oral ad- ministration of tryptophan in rats. Basic Clin Pharmacol Toxicol. 2009;104(1):52-9.

8. Bongaerts J, Kramer M, Muller U, Raeven L, Wubbolts M. Metabolic engineering for microbial production of aromatic amino acids and derived compounds. Metab Eng. 2001;3(4):289-300.

9. Mateus DM, Alves SS, Da Fonseca MM. Kinetics of L-tryptophan production from indole and L-serine catalyzed by whole cells with tryptophanase activity.J Biosci Bioeng. 2004;97(5):289-93.

10. Azuma S, Tsunekawa H, Okabe M, Okamoto R, Aiba S. Hyperproduction of l-trytophan via fermentation with crystallization. Appl Microbiol Biotech. 1993;39(4-5):471-6.

11. Nyeste L, Pécs M, Sevella B, Hollo J. Production of L-tryptophan by microbial processes. Downstream Processing.. Germany: Springer; 1983. pp. 175-202.

12. Bandiera M, Morpurgo G, Ricci R. Tryptophan production by $\mathrm{mu}-$ tant strains of Escherichia coli K12. Experientia. 1967;23(9):724-5.

13. Hagino H, Nakayama K. L-Tryptophan production by analog resistant mutants derived from a phenylalanine and tyrosine double auxotroph of Corynebacterium glutamicum.. Agricu Biol Chem. 1975;39(2):343-9.

14. Roy A, Mukhopadhyay SK. L-Tryptophan production by auxotrophic and analogue resistant mutants of Aureobacterium flavescens. Int J Tryptophan Res. 2011;4:39-46.

15. Matsui K, Ishida M, Tsuchiya M, Sano K. Construction of tryptophan-producing recombinant strains of Brevibacterium. lactofermentum using the engineered trp operons. Agricu Biol Chem. 1988;52(7):1863-5.

16. Chan EC, Tsai HL, Chen SL, Mou DG. Amplification of the tryptophan operon gene in Escherichia coli chromosome to increase 1tryptophan biosynthesis. Appl Microbiol Biotech. 1993;40(2-3):301-5.

17. Bang WG, Lang S, Sahm H, Wagner F. Production L-tryptophan by Escherichia coli cells. Biotechnol Bioeng. 1983;25(4):999-1011.

18. Eggeling L, Pfefferle W, Sahm H. Amino acids. In: Ratledge C, Kris tiansen B editors. Biotechnology.. England: Cambridge University Press; 2004. pp. 335-56.

19. Sumpter WC, Miller FM. The chemistry of heterocyclic compounds indole and carbazole systems. 2nd edNew York: International Publishers Inc; 2003.

20. Skogman GS, Sjostrom JE. Factors affecting the biosynthesis of Ltryptophan by genetically modified strains of Escherichia coli.J Gen Microbiol. 1984;130(12):3091-100.

21. Mohammed N, Onodera R, Khan RI. A new determination method of tryptophan and its related compounds by high-performance liquid chromatography and its application to rumen fluid. Anim Sci Tech. 1998;69:1020-8.

22. Mohammed N, Onodera R, Khan RI. Tryptophan biosynthesis and production of other related compounds from indolepyruvic acid by mixed ruminal bacteria, protozoa, and their mixture in vitro. J Gen Appl Microbiol. 1999;45(4):143-7.

23. Boctor FN, Ragheb H, Kamel MY, Hamed RR. A colorimetric method for the determination of indole, and its application to assay of tryptophanase. Anal Biochem. 1978;86(2):457-62.

24. Tittsler RP, Sandholzer LA. The bacteriostatic action of indole on Gram-negative enteric bacilli and on certain cocci . J Infect Dis. 1935;57(1):64-9.

25. Schnackerz KD, Mozzarelli A. Plasticity of the tryptophan synthase active site probed by31p NMR spectroscopy. J Biol Chem. 1998;273(50):33247-53.

26. Dawes EA, Happold FC. The tryptophanase-tryptophan reaction; the nature, characteristics and partial purification of the tryptophanase complex. Biochem J.1949;44(3):349-61.

27. Dehghan Shasaltaneh M, Fooladi J, Moosavi-Nejad SZ. L-tryptophan production by Escherichia coli in the presence of Iranian cane molasses. J Paramed Sci. 2010;1(2):25-32.

28. Faghfuri E, Fooladi J, Sepehr S, Moosavi-Nejad SZ. L- Tryptophan Production by Whole Cells of Escherichia coli Based on Iranian Sugar Beet Molasses. Jundishapur J Microbiol. 2013;6(4).

29. Chapman HL. Blackstrap molasses for beef cows. Flu Agr Exp Sta Bull.1965;1:701-11. 


\section{Sadeghiyan-Rizi Tet al.}

30. Bang WG, Behrendt U, Lang S, Wagner F. Continuous production of L-tryptophan from indole and L-serine by immobilized Escherichia coli cells. Biotechnol Bioeng. 1983;25(4):1013-25.

31. Ribeiro MHL, Prazeres DMF, Cabral JMS, Fonseca MMR. Adsorption studies for the separation ofl-tryptophan froml-serine and indole in a bioconversion medium. Bioprocess Engin. 1995;12(1-2):95-102.

32. Mateus DMR, Alves SS, Fonseca MMR. Model for the production of L-tryptophan from L-serine and indole by immobilized cells in a three-phase liquid-impelled loop reactor. Bioprocess Engin. 1996;14(3):151-8.
33. Langrene S, Sicsic S, Le Goffic F. Entrapment of l-tryptophan producing Escherichia coli in different matrices: activity of immobilized cells. Enzyme Microb Technol. 1984;6(2):81-4.

34. Hendrikson R, Kesterson JW. By-products of Flurida citrus: composition technology and utilization. Fla Agr Exp Sta Bull. 1965:698.

35. Curtin LV. Effect of processing on nutritional value of feeds: sugar crops. In: Rechigl J editor. Handbook of nutritive value of processed food. Boca Raton: CRC press; 1982. pp. 239-49. 